\title{
Indigenous Knowledge use in seasonal weather forecasting in Tanzania: the case of semi-arid central Tanzania
}

\author{
Emmanuel F. Elia ${ }^{1}$ \\ 211550436@stu.ukzn.ac.za
}

\author{
Stephen Mutula ${ }^{2}$ \\ mutulas@ukzn.ac.za
}

Christine Stilwell

stilwell@ukzn.ac.za

\begin{abstract}
Received: 27 February 2014
Accepted: 22 June 2014
\end{abstract}

This paper is based on part of the findings of a PhD study that was carried out to determine how farmers have used indigenous knowledge (IK) to adapt to climate change and variability in the semiarid region of central Tanzania. Two villages, Maluga and Chibelela, were used as the case studies. The study applied Rogers' (2003) Diffusion of Innovations theory and model. It adopted a predominantly qualitative approach and a post-positivist paradigm. The study population was made up of farmers, agricultural extension officers and the Climate Change Adaptation in Africa project manager. The principal data collection methods were interviews and focus group discussions. The qualitative data collected were subjected to content analysis whereas quantitative data were analysed with the help of SPSS to generate descriptive statistics. The findings revealed that the farmers in the two villages under study perceive conventional information on weather as unreliable and untimely. Consequently, the farmers turned to IK to predict weather patterns and make the necessary farming adjustments. It was established that uncertainty about seasonal weather forecasts is one of the most critical factors which forces farmers to continue using IK. Farmers' knowledge of birds, insects, plants, animals, wind direction and astronomical indicators is used to predict weather patterns. The recommendations include the provision of timely and accurate weather forecast information to the farmers to enhance their coping and adaptation strategies under varying climate conditions; and a clear policy framework on the dissemination of information related to weather patterns in rural Tanzania.

Keywords: Seasonal weather forecasting, climate variability, indigenous knowledge, climate change, semi-arid regions, Tanzania

\section{Introduction}

The Inter-governmental Panel on Climate Change (IPCC) (2001) and the Assessment of Impact and Adaptation to Climate Change (AIACC) (2005) point out that climate change and variability will continue to affect water resources, agriculture, forestry, fisheries, human settlements, ecological systems and human health adversely in many parts of the world, including Tanzania. Hellmuth et al. (2007) note that the majority of people (70\%) in sub-Saharan Africa depend on rain-fed subsistence agriculture. Consequently, in the face of climate change and variability, they are hard hit by unreliable weather patterns. Devereux and Edward (2004) observe that countries in East Africa, where Tanzania is situated, are already among the most food insecure in the world and climate change and variability exacerbates the situation. Climate change and variability in East Africa has both direct and indirect impact on development via climatedependent factors such as infrastructure, agriculture, poverty, conflict, health and education (Devereux \& Edward 2004, Orindi \& Murray 2005).

1. Emmanuel F. Elia is a PhD candidate at the University of KwaZulu-Natal, South Africa.

2. Professor Stephen M. Mutula is Acting Dean and Head of the School of Social Sciences at the University of KwaZulu-Natal, South Africa.

3. Christine Stilwell is Emeritus Professor, Information Studies, University of KwaZulu-Natal, South Africa. 
In Tanzania, research studies conducted in the central regions by Lema and Majule (2009), Majule and Yanda (2009) and Mongi, Majule and Lyimo (2010) revealed that climate change and variability has adverse effects on agriculture. They note that climate change and variability is responsible for prolonged droughts and the unpredictability of rainfall.

\section{Statement of the problem}

One of the major factors impacting the achievement of the first Millennium Development Goal (MDG) ${ }^{4}$ in Tanzania, according to the National Action Programme for Adaptation (NAPA) of the United Republic of Tanzania (URT 2007), is climate change and variability. Climate change and variability has adverse effects on agricultural production as a result of prolonged droughts, floods, and increased incidence of disease and pests (Lema \& Majule 2009, Mongi, Majule \& Lyimo 2010). Kandji and Verchot (2007) observe that Tanzania, like most countries in Africa, depends on rain-fed agriculture to improve its level of food security. Recently, however, because of erratic rainfall, rain-fed agriculture has been less reliable in promoting food security than in the past.

Chang'a, Yanda and Ngana (2010) have asserted that, in East Africa more generally, the increase in climate change and variability in most parts of the region has led to increased uncertainty in forecasting seasonal rainfall. Because of this uncertainty, farmers are making use of Indigenous Knowledge (IK) in farm decision-making. This is particularly true of environments where there is a lack of reliable, timely, accessible and appropriate weather information. This situation highlights the critical challenge which scientists face in seeking to forecast weather patterns reliably. The provision of relevant, accessible and timely information to farmers, especially those dependent on subsistence farming, is needed to boost their farming production.

This study was carried out in the two villages of Chibelela and Maluga in the Dodoma and Singida regions of Tanzania. These regions are populated largely by peasant farmers. The study aimed at investigating how the traditional peasant farmers use IK to predict weather and to adapt to climate change and variability. This article addresses two research questions:

1. To what extent is IK used in weather forecasting in the study villages?

2. What are the farmers' perceptions of the reliability of weather forecasts?

\section{Review of the literature}

There are an increasing number of studies on the use of IK in weather forecasting. A study by Chang'a, Yanda and Ngana (2010) revealed that, despite the majority (96\%) of rural people in Tanzania being aware of seasonal forecast information, only 58 percent use such information to plan farm activities. Orindi and Murray (2005) observed that farmers in East Africa generally are not using seasonal weather forecasts effectively owing to challenges in the collection and timely dissemination of such information.

Unlike national weather forecasts, IK forecasts are produced locally by people whose forecasts are based on their past experience of biophysical and spiritual indicators (Orlove et al. 2010, Roncoli, Ingram \& Kiershen 2002). Prior to the introduction of scientific seasonal climate forecasts, locally-based farmers used IK for farming and in response to anticipated disasters such as floods and droughts (Adejuwon, Odekunle \& Omotayo 2008). Naess (2013) reveals more significantly that in Tanzania IK has the potential to enhance farmers' adaptation to climate change and variability.

An abundance of literature shows that a number of African farmers have been using various local weather indicators such as plants, animals, insects, the solar system and wind in predicting the seasonal climate (Roncoli, Ingram \& Kiershen 2002, Tarhule \& Lamb 2003, Speranza et al. 2010, Ziergovel \& Opere 2010). In Tanzania, Kihupi et al. (2002), Slegers (2008), Chang'a, Yanda and Ngana (2010), Kangalawe, Mwakalila and Masolwa (2011), Mahoo and Mpeta (2011), Kijazi et al. 2013 and Naess (2013) are among scholars who have examined how farmers use IK in coping and adapting to climate change and variability in various regions of Tanzania.

The study by Chang'a, Yanda and Ngana (2010) found that farmers in Tanzania use indicators such as plants, birds, insects and astronomy in weather prediction. These findings corroborate those of Kihupi et al. (2002) and Kijazi et al. (2013) which revealed that, prior to the introduction of scientific weather forecasts, rural people depended on IK for weather forecasts. The findings by Kihupi et al. (2002) and Kijazi et al. (2013) revealed further that people use the behaviour of mammals, birds, insects and plants to predict the coming agricultural season. Similarly, Slegers' (2008) study found that farmers in Tanzania use IK to understand the weather patterns of the coming season. They predict weather by observing signs of natural phenomena such as trees and stars which they believe originate from "the hands of God". However, Slegers' (2008) study also revealed that the farmers' dependence on IK in forecasting seasonal patterns is rapidly waning due to the increasing unreliability of the IK-based forecasts.

A study in Kenya by Speranza et al. (2010), which investigated farmers' use of IK and the adaptation to climate change and variability in semi-arid areas of the East African country, found that farmers possess knowledge on the use of local indicators in predicting rainfall. The study further established that the farmers believe in and rely on the efficacy of IK as the basic knowledge system within which they interpret meteorological forecasts and make decisions pertaining to their agricultural practices.

4. The first MDG aims at eliminating poverty and hunger by 2015. 
Hisali, Birungi and Buyinza (2011) investigated farmers' adaptation to climate change in Uganda. They observed a notable difference in the choice of adaptation strategies by farmers and stressed that for adaptation strategies to receive attention, IK use by farmers should be encouraged. Also in Uganda, Orlove et al. (2010) observed that farmers use IK in seasonal climate forecasts and emphasised that incorporating farmers' IK with scientific knowledge is crucial in designing, developing and disseminating forecasts for effective adaptation. In the semi-arid areas of Zimbabwe, Mutekwa (2009) found that farmers rely more on IK than on conventional seasonal forecasts via extension agents. Generally, farmers interviewed for the current study demonstrated a high level of ignorance of conventional seasonal climate forecast information. As a result, they fail to utilise this information in making effective farming decisions. It is apparent from these cited studies that local farmers, particularly the peasant population, rely on IK for predicting weather and making farming decisions. However, there is limited understanding of how the use of IK can be combined with conventional weather forecast information to predict climate change and variability. This article seeks to throw light on this research gap.

\section{The applicability of the Diffusion of Innovations (DOI) theory and model to the study}

Rogers (2003:12) defines an innovation as any idea, object or practice that is perceived as new by members in a social system. Innovation in this study is perceived in the context of seasonal weather forecast information which has been introduced to farmers to enhance adaptation to climate change and variability. Diffusion is the process by which an innovation is communicated through certain channels, over time, and among the members of a social system (Rogers 2003: 5).

The DOI is a useful framework and model as it explains attributes such as relative advantage, trialability, observability, knowledge, attitude to change, and compatibility, which are crucial in understanding how farmers use information in adapting to climate change and variability.

The DOI model has had a major influence in the way information is disseminated to end-users, such as farmers, and in creating awareness about innovation adoption factors (Rogers 2003). The channels through which users access information are important for creating knowledge and for changing peoples' attitudes to innovations. These channels of communication enhance the flow and the exchange of information among users by facilitating farmers' access to, and use of, such information.

\section{Methodology}

This study was part of a broader PhD study (Elia 2014) which investigated how access to, and use of, information enhances adaptation to climate change and variability in the agricultural sector in central Tanzania. Data were collected from subsistence farmers in Maluga and Chibelela villages, in Singida and Dodoma regions respectively. The study villages were randomly selected from other villages in Dodoma and Singida which had all been exposed to the Climate Change Adaptation in Africa (CCAA) project. The CCAA aimed at creating awareness about coping strategies with uncertain weather changes. Using purposive and snowballing sampling techniques, eighty-four respondents were chosen from the collection of farmers to participate in the interviews. The study focused on farmers who mainly engaged in crop production.

A post-positivist approach was used to conduct the qualitative and (to a certain extent) quantitative aspects of the study using interviews and focus group discussions (FGDs). Besides the population of farmers, agricultural extension officers and the CCCA project manager were included in the study. One FGD, constituting eight participants, was carried out in each study village. Both semi-structured interviews and FGD checklists ${ }^{5}$ were used to collect information from the farmers on a number of issues related to the use of IK in weather prediction. The questions in the research instruments solicited information on whether IK on weather prediction existed among the farming community; the type of IK farmers used for weather forecasting; and whether IK was reliable for weather prediction. Data collected were analysed both qualitatively and quantitatively. Qualitative data was subjected to content analysis whereas quantitative data was analysed descriptively to generate descriptive statistics such as percentages and frequencies with the aid of SPSS.

\section{Results}

This section presents the study findings on the existence and use of IK for weather forecasts in the villages under study. It also presents findings on farmers' perceptions of the reliability of weather forecasts.

\subsection{Socio-economic profiles of the respondents}

There were more female (fifty-eight; 69\%) than male (twenty-six; 31\%) farmer respondents. Maluga village had twenty $(55.6 \%)$ female and sixteen (44.4\%) male respondents. Chibelela village had thirty-eight $(79.2 \%)$ female and ten $(20.8 \%)$ male respondents. The ages of the respondents ranged from fifteen to sixty. Most of the respondents (sixty-three; $75 \%$ of the total) were primary school leavers, twelve (14.3\%) were illiterate and eight (9.5\%) had some secondary education. Only one (1.2\%) respondent had a post-secondary (college or university) education. Of the eighty-four respondents interviewed, the majority was involved in farming activities to earn a living. Specifically, seventy-eight (92.8\%) of the

5. Available from the first author. 
respondents indicated that farming was their primary source of income. Only six (7.2\%) of the respondents indicated that they did not depend entirely on farming as their major economic activity.

\subsection{Indigenous indicators used by farmers for weather prediction}

Communities evaluate local weather and climate change based on their experiences through their interaction with the environment. The study found that IK exists in the communities and farmers use local indicators to forecast weather and forthcoming seasons in a given year. The farmers in Maluga and Chibelela villages were found to use plant phenology, animals, insects, the solar system, wind and the behaviour of birds in forecasting weather. In this section, the key findings on the IK local indicators used by farmers in Maluga and Chibelela villages are presented and discussed.

\subsubsection{Indicators from plants}

During the FGDs and semi-structured interviews, it emerged that the farmers in Chibelela village use plant phenology such as the sprouting of tree leaves, flowering, and plant growth size to predict rainfall onset and a good or bad crop year.

When rain is about to start, tree species known as the Plum Fingerleaf (Vitex ferruginea), locally identified as Mfuru, Bloodwood/Sealing Wax (Pterocarpus angolensis), locally known as Mninga, Large-leaved Dalbergia (Dalbergia boehmii), locally known as Mnyinga, the Baobab (Adansonia digitata), locally known as Mbuyu, Mgole (the English and scientific name could not be identified) and Acacia (Acacia tortilis), locally known as Mkunguu, produce leaves and flowers which farmers use as indicators for forecasting the upcoming rainy season.

The study also found that the local farmers use the morphological features of trees locally known as Mgole and Msonankanga (the English equivalent and scientific names could not be identified) to predict weather. Apart from being used to predict rainfall, the Mgole tree is used to signify a good or bad year, that is a year with either enough or scarce rain. During the FGDs, it was further established that the Mgole tree possesses a unique feature that indicates the onset of rain: the tree grows upright in the dry season and, when it bends, it signals the imminence of rainfall. Similarly, Msonankanga is a seasonal plant which has a unique feature observed by the locals that indicates the change of season: the plant grows tall with the onset of rain and is short when there is no rain.

Further findings showed that the Mnyinga tree, which is also known as Large-leaved Dalbergia (Dalbergia boehmii), is used to predict a good or bad rainfall season. When the Large-leaved Dalbergia tree partially sheds its leaves, rain follows. To the villagers this signifies a good year or season. Conversely, when the Dalbergia trees shed their leaves completely and produce flowers before the rainy season commences, a bad year or season is indicated. The study findings indicate that, when most Large-leaved Dalbergia tree species produce and shed flowers partially before the rainy season begins, villagers consider it a good omen of a season with enough rainfall and hence a good crop. On the other hand, when most Dalbergia trees produce and shed all of their flowers and there is a delay in the onset of rains, villagers consider it an omen of a season with scarce rainfall.

In Maluga village, plants used to forecast weather are identified as Large Sourplum (Ximenia caffra), locally known as Mtuundwa, Large-leaved False Thorn (Albizia versicolor), locally identified as Mzuu, Acacia trees (Acacia tortilis), locally known as Mguunga, Mtamba (English and scientific names could not be obtained), Large-leaved Dalbergia (Dalbergia boehmii), locally known as Mpogolo, Christmas/Flamboyant trees (Delonix regia), locally identified as Mkrismasi, and Msunzu (English and scientific names could not be identified).

Other trees that the villagers rely on for forecasting the weather patterns include the Myrrh (Commiphora sp.), locally known as Msaghaa, Mlandala (English name could not be identified), Wing Pod (Xeroderris stuhlmanni), locally identified as Munene, Mkuyu (English name could not be identified), Mnkola (English and scientific names could not be identified), Msalumbi (English and scientific names could not be identified), Mtulu (English and scientific names could not be identified) and the Baobab. The study found that farmers use the emergence of fresh tree leaves, flowers and fruits to predict the onset of rain. When rainfall is about to commence, trees produce leaves and flowers, and farmers use these local indicators to prepare for the new season's farming activities. It was further established that Msalumbi and Mtuundwa trees produce fruits which ripen when rainfall is imminent. Although findings show that farmers widely use plants in weather prediction, it was revealed that the plant species which they have used in the past are disappearing at an alarming rate.

\subsubsection{Indicators from birds}

The study found four bird species which are commonly used by farmers to predict a good or bad season in Chibelela village. These are the white-browed coucal (Centropus superciliosus) also known locally as Dudumizi, cattle egret (Bubulcus ibis) locally known as Yangayanga, wire-tailed swallow (Hirundo smithii) locally known as Samamba/Mbayuwayu, and birds locally known as Yobwa (English and scientific names could not be identified). The villagers reported that the appearance of white-browed coucals signifies the onset of the rainy season. Indeed, when the coucals produce a certain chirp and chirrup in a particular way at night in November, the villagers are convinced that rainfall is imminent. The study findings further indicated that, in most cases, the white-browed coucals appear when rainfall resumes after it has stopped for a while. Besides, when the Yobwa birds appear, moving from west to east in October, it is a sign of a good year, according to the villagers. Conversely, the delay of the Yobwa birds' appearance, until November for example, is indicative of a bad year.

Another bird weather indicator is the appearance of cattle egrets (Bubulcus ibis) in a village, which the villagers interpreted as a signal for a bad season, particularly when their appearance is characterised by the death of cattle and an outbreak of livestock diseases. In addition, the appearance of wire-tailed swallows (Hirundo smithii) in large numbers in 
the sky is taken by the villagers to signify the onset of rains and leads to the prediction of imminent heavy rainfall. The study findings established, however, that the appearance of these birds these days is becoming increasingly rare.

In Maluga village, the study findings from the interviews and the FGDs indicated that the birds used as local indicators for weather predictions are white-browed coucals (Centropus superciliosus), also locally known as Dudumizi, wire-tailed swallow (Hirundo smithii), locally identified as Samamba, Nkuunguza (English and scientific names could not be identified), Nsiigu (English and scientific names could not be identified), cattle egret (Bubulcus ibis), locally known as Nangenange, and Kinkiingoma (English name could not be identified). These birds are used to predict the onset of rains and a good rainfall season.

It was learned that the appearance of white-browed coucals, moving and singing in groups early in the morning (around 05h00) in October and November, signifies imminent rainfall and a good year ahead. Furthermore, it was found that wire-tailed swallows appearing in groups during the onset of the rains is an indication of heavy rainfall to come. Besides, the appearance in November of a bird species identified as Kinkiingoma, accompanied by their distinctive call, indicates the rainfall onset and heavy rainfall. Similarly, it was found that the appearance of Nkuunguza, cattle egrets and Nsiigu birds in large numbers forecasts rain and a good harvest in a given season. It was noted by farmers that the use of birds in weather prediction is becoming difficult as the various species are disappearing at a disquieting rate.

\subsubsection{Indicators from amphibians, insects and mammals}

The study also found that the villagers use frogs (of various species) as local indicators for weather prediction. Farmers in Chibelela village, for example, explained that frogs appear and produce a certain sound continuously when rainfall is imminent in a particular season. The respondents explained that when frogs delay making the sound, the silence signals that the rainy season is yet to start.

The study findings from both the interviews and FGDs further established that insects such as millipedes (various species), army worms (Spodoptera exempta), termites (Ancistrotermes sp.), butterflies (various species), grass-green grasshoppers (Hesperotettix sp.) and insects locally known as Mbilazi (English and scientific names could not be identified) are also used in weather prediction by the villagers.

Indeed, the villagers use insects in particular to predict the weather. Specifically, the villagers consider the appearance of millipedes, grass-green grasshoppers and butterflies appearing in great numbers in a season as a sign that rain is imminent, and the emergence of grass-green grasshoppers in abundance as a sign of a good harvest year. On the other hand, the villagers consider the appearance of caterpillars in January or February, after the rainfall season, as an indicator of an imminent food famine in the village. Moreover, the study found that, though termites (Ancistrotermes $s p$.) are not being used in rainfall prediction, their appearance after the rainfall season in large numbers is taken to signify famine as they destroy the already-cultivated crops. In addition, it was learned that when Mbilazi insects are green in colour, heavy rainfall is imminent; their appearance as red, on the other hand, signifies less rainfall in a season.

The study findings showed that farmers in Maluga village, just as in Chibelela village, use amphibians and insects to predict weather. In Maluga, as in Chibelela village, the farmers reported using frogs to predict weather. In this regard, farmers explained that the appearance of frogs producing a unique sound signifies the rainfall onset.

It was ascertained that the insects used for weather prediction in Maluga village are termites (Ancistrotermes sp.), grass-green grasshoppers (Hesperotettix sp.), locally known as Senene, caterpillar/host larvae (Melachaka jeseri) and millipedes (various species), and an insect locally identified as Mlilyanondoo. The appearance of termites on the ground indicates the beginning of the rainy season. In particular, when Mlilyanondoo insects appear and make a noise, they signal that the rain is about to start, whereas the appearance of grass-green grasshoppers signifies both the imminence of rain and a good year. When the caterpillar/host larvae appear after the rainfall season (January), villagers predict food shortages in the locality.

The study further discovered that in Maluga village the farmers use the sounds produced by hyenas to predict the rainfall onset. Notably, it was found that certain calls of the hyena (Crocuta crocuta) mean imminent rainfall - the kind of sound produced by the animal coincides with the onset of the rain.

\subsubsection{Indicators from wind direction and stones}

The study findings show that farmers in Chibelela and Maluga villages use wind and dust direction to predict the onset of rainfall, the amount of rainfall, and continuity of rainfall in a season. Farmers in Chibelela explained that strong winds and dust in October or November blowing from east to the west signifies the beginning of the rains and a good year. The wind and dust direction from the west to the east signifies less rainfall in that season, which to the villagers is a bad omen and predicts a bad year. During the FGDs, the participants admitted that it was difficult to predict the amount of rainfall by simply observing wind or dust direction. In fact, the majority of farmers participating in the study are able to forecast the imminence of rainfall, but not the expected quantity. Findings from the FGDs also indicated that wind direction is used to show the resumption of rainfall after a lull in the rain.

It was established from Maluga farmers that they also use wind direction to predict both the onset of rain and the expected amount of rainfall in a given season. For example, when farmers observe strong winds from west to east from September to November, they consider it a sign of imminent heavy rainfall in the upcoming season. When the wind direction is from east to west in July, farmers consider it a bad omen, an indicator of less rainfall in the upcoming season. When this happens, farmers predict a bad year. The farmers pointed out that when they observe heavy dust moving from the south to the north, they regard it as a sign of imminent rainfall. 
The study found that, in the past, farmers also used stones to predict rainfall. The findings from both the interviews and the FGDs confirmed that a few elderly farmers still possess knowledge on the special stones that were used in predicting weather. In the FGDs a farmer explained:

When the rainfall season was near, elders who were believed to be traditional healers took blood from a chicken and placed it on special stones which are round in shape...The elders left the special stones for one night and collected them in the morning. If the stones were covered with a significant quantity of water, it signified immense rainfall and, if covered with less water, this meant low rainfall in the coming season.

It was learned that these days the use of such special stones in weather forecasting is being practised less or has been abandoned altogether.

\subsubsection{Indicators from the solar system}

Findings from farmers in Chibelela village indicate that they use the moon and the stars to predict rainfall. When farmers observe a halo of light around the moon, they believe it signifies that the moon is surrounded by water and that this forecasts rain. When the moon is surrounded by clouds, the villagers believe it signifies that rain will fall in small quantities, but will last for a long period. The consecutive appearance of a semi-circular moon positioned in the north forecasts rainfall.

FGD findings in Maluga village showed that these farmers also use the shape of the moon and its colour to predict rainfall. It was established that farmers predict a good rainfall season when the moon's shape is oval, with a small black spot in the middle, and it is surrounded by clouds. When the moon is shrouded by clouds and black spots appear surrounding the moon, the villagers predict the onset of heavy rainfall. When the moon is red, the villagers anticipate high rainfall and when it is white, they forecast low rainfall. On the whole, villagers use the moon's shape and colour to see signs of the amount of rainfall and to predict a season of either sufficient or scarce rainfall.

The study found that the position and number of visible stars are used to foretell rainfall in a particular season. Villagers use stars to predict the amount of rainfall and the onset of the rain. They use a particular type of star, whose movements they observe, to make inferences about the rainfall patterns for a specific season of the year. According to the study respondents, the early emergence of a star known as Nangakavuji (the English name of this star and Nimila stars below could not be identified) in mid-November in the west, as it moves from the east, signifies a good rainfall season. If the star delays its appearance within a set timeframe, a bad season with less rainfall, is predicted.

The FGD findings revealed that, in both villages, the appearance of a group of stars known as Nimila, which move from the east to the west, signifies the amount of rainfall in a season, when positioned in a particular referenced location. Farmers identify the sun's position in the morning and compare its position with the Nimila stars. The movement of the Nimila stars is observed continuously from mid-November to mid-December. When Nimila stars reach a certain position in the evening, farmers predict rainfall and a good season. If they do not reach the designated position during midDecember, the villagers interpret that as a sign of delays in the onset of the rainfall season. If Nimila stars pass the designated position when viewed in mid-December, the villagers anticipate that the season will be a bad one, with scarce rainfall.

With regard to the use of sun and temperature in predicting weather, the study findings show that farmers in Maluga village interpret high temperatures from September to November as signifying the rainfall onset. Also, when the sun is positioned in the southwest during the rainfall season, the villagers see that as signifying imminent rain. On the other hand, when the sun is positioned in the northwest, it is a signal of the beginning of the summer season.

\subsection{Farmers' perceptions of IK's reliability in weather forecasting}

From Maluga and Chibelela villages, it was established that farmers use and rely more on IK forecasts (IKFs) than on seasonal climate forecasts (SCFs). Uncertainty about seasonal weather forecasts is the critical factor which forces farmers to continue using IKFs despite the increasing availability of, and need to use, SCFs. These findings are supported by the DOI which emphasises relative advantage and observability as important factors in the adoption of innovations (Rogers 2003). This study found that at this local level, IK usage is deemed essential by the largely peasant farmers in their adaption to climate change and variability.

Despite IK use for weather prediction being crucial in adapting, the findings of the study from FGDs indicated that age is an important determinant explaining farmers' ability to understand and interpret IK. Findings showed that, despite many farmers indicating that they possess IK on weather prediction, elderly farmers have more IK on weather prediction compared to young ones. Elderly farmers can forecast the pattern of rainfall for the next season, unlike younger farmers.

\section{Discussion of the results}

The results show an over-reliance of rural farming communities in Tanzania on IK for weather prediction. Nyong, Adesina and Elasha (2007) observed that rural communities use IK as the basis for local-level decision-making, including matters involving weather forecasting. A study by Naess (2013) in the semi-arid areas of Tanzania noted that IK facilitates farmers' adaption to climate change and variability. Chang'a, Yanda and Ngana's (2010) study established that in the south-western highlands of Tanzania farmers use the phenology of trees such as Erythrina abyssinica and Brachystegia 
speciformis in predicting rainfall. Other findings from the south-western highlands show that farmers use the behaviour of white-browed coucal (Centropus superciliosus) birds to forecast weather patterns. Luseno et al. (2003) conducted a study in Ethiopia and Kenya and found that pastoralists make use of a range of local indicators such as wind, clouds, lightning, moon, stars, wildlife, livestock, local plants and intestines of slaughtered animals to predict the forthcoming season and weather patterns. These earlier findings are largely consistent with those of the present study, which show that farmers use birds, amphibians, mammals, insects, plants and the solar system as indicators to predict weather and even the amount of rainfall to expect.

Findings by Roncoli, Ingram and Kirshen (2002) in Burkina Faso revealed that flowering of fruit trees and good yields from trees such as mango, sibga and taanga (English and scientific names of latter two could not be identified) signify abundant rainfall and a good season. The Burkina Faso study shows that, to the farmers, fruiting of sibga and loss of leaves by sabtuluga tree species (English and scientific names were not identified) signal the time for planting. These findings confirm those of the present research as the farmers in the study areas associated the ripening of the Mtuundwa (Ximenia caffra) with increased yields and the ripening of the Msalumbi with adequate and imminent rainfall. Roncoli, Ingram and Kirshen's (2002) study found that the positioning of fruits in a tree meant higher yields of particular crops such as sorghum for that season.

The findings of this study indicate that farmers in the two Tanzanian villages use the behaviour of insects in predicting weather. The useful insects in this regard include the millipede (various species), army worms (Spodoptera exempta), termites (Ancistrotermes sp.), butterflies (various species) and grass-green grasshoppers (Hesperotettix sp.). Other useful insects in this regard are the caterpillar/host larvae (Melachaka jeseri) and Mlilyanondoo and Mbilazi. These findings are in line with those of Roncoli, Ingram and Kirshen (2002) who found that farmers in Burkina Faso used bugvare insects (Orthoptera sp.), which are black in colour, to predict weather. When the bugvare appear after the first rains and fill their nests to the brim with dirt, the villagers consider it to signify that adequate food will be available. A study by Roncoli, Ingram and Kirshen (2002) has shown that the appearance of large numbers of mayflies during the maize planting season foretells an imminent good season. Chang'a, Yanda and Ngana's (2010) study confirms the current study findings to the effect that butterflies, ants and termites are used by farmers in south-western highlands of Tanzania to forecast what the coming farming season will be like.

Specifically, the findings from Maluga and Chibelela villages indicated that farmers use and rely more on IKFs than SCFs. Sleger (2008) established that in Tanzania IK is relied upon and used by the local farmers in the semi-arid Kondoa district. These findings confirm those of Orlove et al. (2010) who found that farmers in Uganda use IK in seasonal climate forecasts for planning their farming activities. Similar findings were reported by Speranza et al. (2010) who revealed that farmers in Kenya possess and rely on IK to interpret rainfall variability.

The use of and reliance on IK in farming may be explained by two factors. The first is the uncertainty about seasonal weather forecasts. Chang'a, Yanda and Ngana (2010) noted that the increase in climate variability in most East African countries has resulted in an increase in distrust of seasonal rainfall forecasting. Tarhule and Lamb (2003) discovered that access to reliable and accurate seasonal rainfall information can improve food security and farmers' ability to respond to observed climate variations.

The other reason behind the farmers' dependence on IK has to do with the vast knowledge and experience the farmers have accumulated over years of practising farming in their localities. This knowledge has been passed on from one generation to another. Adejuwon, Odekunle and Omotayo (2008) and Chang'a, Yanda and Ngana (2010) noted that farmers in Africa used IK practices before scientific weather forecast information was introduced. This IK knowledge has been gathered through their interaction with their respective environments. In fact, the local farmers' knowledge of their environment is enhanced by their ability to observe and study the local weather indicators (Nyong, Adesina \& Elasha 2007). The reasons for farmers' use of and reliance on IK are attested to by the DOI (Rogers 2003). DOI describes knowledge, complexity, compatibility, observability, prior experience, observability and relative advantage as important features which influence individuals' use of innovations (Rogers 2003). Nyong, Adesina and Elasha (2007) found farmers in the Sahel to have devised means of forecasting and interpreting weather to improve their agriculture. The Sahel study's key findings show that farmers apply IK to choose planting dates and cropping patterns. The study established that the local indicators used by farmers to forecast weather are useful and enhance their adjustment to climate change and variability. These findings are consistent with the DOI model which explains relative advantage to be crucial in influencing adoption of innovations. Thus, based on the usefulness of information disseminated, farmers will be motivated to adopt innovations.

Orlove et al. (2010) learned that farmers in southern Uganda use local indicators such as flowering of trees, unique phases and shapes of the moon, appearance of whirlwinds, increased night time temperatures and arrival of migratory birds, identified as Abyssinian hornbill (Bucorvus abyssinicus), to predict upcoming weather. Similarly, in the current study, farmers use trees, birds, moon, wind and temperature to predict the upcoming weather. A study conducted in Andean, Southern America, by Orlove, Chiang and Cane (2000) found that farmers who cultivate potatoes use local astronomical indicators such as stars and the colour of the sky to predict weather for the next season. It is apparent that the use of traditional knowledge and wisdom in predicting weather patterns is not a phenomenon restricted to the villages under study but is found among native peoples in other areas in Tanzania, other African countries, and abroad. These findings are elucidated by the DOI which explains the role of individuals' prior knowledge in adopting innovations. In this regard, as observed in the study, since farmers possess IK, the DOI model can be used to build on the prior knowledge farmers have to enhance adaption. 
Findings by Roncoli, Ingram and Kirshen (2002) revealed that the appearance of a group of stars identified as Souci (Pleiades) in early May indicates the onset of rainfall and that it is time for farmers to start preparing their farms for harvesting. These authors observed that the shape and location of the moon explains the rainfall pattern. Farmers apply their IK to interpret the weather pattern and make decisions on what crop to be grown in a season. These findings confirm the present study results, which indicate that farmers use their IK to identify the position and movement of stars and the moon to forecast weather. Findings of this study show that Nangakavuji and Nimila stars are used by villagers to forecast rainfall onset and whether the upcoming harvest will be good or bad.

A study conducted in West Africa by Tarhule and Lamb (2003) established that, despite the availability of weather forecasts, a significant number of farmers (30\% of their sample) still make use of IK of the weather. The West African study found that farmers are predicting weather and climatic conditions by observing the local indicators such as the stars, wind, colour of the sky, cloud cover and temperature. The study revealed that the main reason for farmers continuing to use IK to forecast weather is that they cannot easily access conventional forecasts. These results confirm those of the present study to the effect that lack of timely access to conventional climate information is affecting the use of seasonal forecasts by the villagers. The DOI model describes the role of communication channels as crucial to users accessing information.

The current study findings and those of Nyong, Adesina and Elasha (2007) and Chang'a, Yanda and Ngana (2010) show that rural communities use tree species to predict weather. Roncoli (2006), on the other hand, found that the farmers do not generally interpret and predict weather using any plant species. Farmers make forecasts on the basis of species of trees located in the proximity of their residence or farms (Roncoli, Ingram \& Kirshen 2002). In this regard, as emphasised by Roncoli, Ingram and Kirshen (2002), at the local level farmers use mostly their IK emanating from their interaction with the environment to make decisions in agriculture. These results are in line with the DOI which shows that prior experience by an individual influences knowledge acquisition and adoption of innovations.

However, the major concern observed in the present study is that, despite local indicators such as trees and birds being used by farmers in weather prediction, these indicators are disappearing at a disturbing rate. A country survey conducted by Gideon, Nyinondi and Oyema (2012) found that Tanzania has a total of 14,336 plant and animal species. These species are relatively fewer than the 24,000 which are known to be native to Tanzania. Although there are many reasons that could explain this discrepancy, climate change and variability could be one of the factors contributing to the inconsistency. Thus, as the type of agriculture practised in Tanzania is largely rain-fed, the disappearance of trees, birds and insects, as well as the non-documentation of IK, threaten farmers' adjustment efforts aimed at mitigating the climate change impacts.

From the study findings, it was established that farmers use both indigenous and scientific knowledge in adapting to climate change and variability. These findings confirm those of Mahoo and Mpeta (2011) who observed farmers using IK and scientific knowledge in reducing climate risks. Farmers' use of a combination of IK and scientific knowledge suggests that neither is currently sufficiently accurate and reliable in informing farmers' decision making. Access is also a problem for younger people, particularly regarding IK. However, the major critical and contentious issue arising from this study is how to enhance the use of IKFs and SCFs to complement one another.

This enhancing can be done through improving the quality of SCFs by providing farmers with timely, relevant, and easily accessible information for decision making (Chikozho 2010). These improvements in the information provided could encourage farmers to use IK and conventional weather forecasts in a complementary manner to enhance decision making. This view resonated well with the DOI model. Upscaled conservation efforts regarding the flora and fauna of Tanzania could enhance the availability of many of the IK indicators in weather forecasts.

\section{Conclusion and recommendations}

The study established the existence, use and perceptions of reliability of IK in weather prediction in the two villages in central Tanzania. The study also identified the local indicators used by farmers for weather prediction in the semi-arid central Tanzania villages of Maluga and Chibelela. The villagers use plant phenology, birds, amphibians, mammals, insects, wind direction and the solar system to predict weather. It was learned that many of the local farmers, and mostly elders, possess IK on weather prediction. Key findings, however, indicate that despite many farmers possessing IK on weather prediction, few of them can forecast the quantity of rainfall for the next season reliably. On the whole, despite these problems, the participating farmers are of the view that local indicators are better indicators of weather forecasts than scientific weather forecasting, to which they have little access anyway.

Furthermore, the results show that IK is on the wane, as some of the indicators the local farmers are accustomed to reading for signs are vanishing because of changes in the environment. The findings from this study indicate that the farmers have recently perceived the reliability and accuracy of the local indicators to have been reduced by climate change and variability. In this regard, to assist the local farmers, timely and accurate weather forecast information is needed. Thus, the study suggests the need for a policy framework which will address the problem of the ineffective dissemination of information related to climate change and variability among local farmers, particularly in the remote rural areas of Tanzania.

\section{References}

Assessment of Impact and Adaptation to Climate Change (AIACC). 2005. Sustainable livelihood approach for assessing community resilience to climate change: case studies from Sudan. AIACC Working Paper; no.17 [Online]. http://www.aiaccproject.org (17 September 2013). 
Adejuwon, J.O., Odekunle, T.O. and Omotayo, M.O. 2008. Using seasonal weather forecasts for adapting food production to climate variability and change in Nigeria. In Climate change and adaptation. N. Leary, A. James, V. Barros, I. Burton, J. Kulkarni and R. Lasco, Eds. London: Earthscan.

Chang'a, L.B., Yanda, P.Z. and Ngana, J. 2010. Indigenous knowledge in seasonal rainfall prediction in Tanzania: a case of the south-western highland of Tanzania. Journal of Geography and Regional Planning, 3(4): 66-72.

Chikozho, C. 2010. Applied social research and action priorities for adaptation to climate change and rainfall variability in the rain-fed agricultural sector of Zimbabwe. Physics and Chemistry of the Earth, 35(13-14): 780-790.

Devereux, S. and Edward, J. 2004. Climate change and food security. Institute of Development Studies Bulletin, 35(3): 22-30.

Elia, E, 2014. Information dissemination for adaptation to climate change and variability in the agricultural sector: the case of Maluga and Chibelela villages, Central Tanzania. PhD thesis. University of Kwazulu-Natal.

Gideon, H., Nyinondi, P. and Oyema, G. 2012. Checklist of Tanzanian species: version 1. Dar es Salaam: Tanzania Commission for Science and Technology and Inter Press of Tanzania Ltd.

Hellmuth, M.E., Moorhead, A., Thomson, M.C. and Williams, J. Eds. 2007. Climate risk management in Africa: learning from practice. New York: Colombia University.

Hisali, E., Birungi, P. and Buyinza, F. 2011. Adaptation to climate change in Uganda: evidence from micro level data. Global Environmental Change, 21(4): 1245-1261.

Inter-governmental Panel on Climate Change (IPCC). 2001. Climate Change 2001: Impacts, adaptation vulnerability's contribution of working group II to the third assessment report of the intergovernmental panel on climate change. Cambridge: Cambridge University Press.

Kandji, S. and Verchot, L. 2007. Impacts of and adaptation to climate variability and climate change in the East African community: a focus on the agricultural sector. Nairobi: Word Agroforestry Centre (ICRAF) [Online]. http://worldagroforestrycentre.net/downloads/publications/PDFS/RP07172.pdf (20 November 2013).

Kangalawe, R., Mwakalila, S. and Masolwa, P. 2011. Climate change impacts, local knowledge and coping strategies in the Great Ruaha River Catchment area, Tanzania. Natural Resources, 2(4): 212-223.

Kihupi, N.I., Kingamkono, R., Rwamugira, W., Kingamkono, M., Mhita M. and Brien, K.O. 2002. Promotion and integration of indigenous knowledge in seasonal climate forecasts. Harare Drought Monitoring Center. [Online]. http://www.sadc.int/dmc/Research/PilotProjects/Promotion\%20And \% 20Integration\%20Of\%20Indigenous\%20 Knowledge\%20In\%20Seasona.pdf (10 November 2013).

Kijazi, A.L., Chang'a, L.B., Liwenga, E.T., Kanemba, A. and Nindi, S.J. 2013. The use of indigenous knowledge in weather and climate prediction in Mahenge and Ismani wards, Tanzania. Journal of Geography and Regional Planning, 6(7): 274-280.

Lema, A.M. and Majule, A. E. 2009. Impacts of climate change, variability and adaptation strategies on agriculture in semi-arid areas of Tanzania: the case of Manyoni District in Singida Region, Tanzania. African Journal of Environmental Science and Technology, 3(8): 206-218.

Luseno, W.K., McPeak, J.G., Barrett, C.B., Little, P.D. and Gebru, G. 2003. Assessing the value of climate forecast information for pastoralists: evidence from southern Ethiopia and Northern Kenya. World Development, 31(9): 14771494.

Mahoo, H. and Mpeta, E. 2011.Combining indigenous and scientific weather forecasting knowledge in climate risk management in semi-arid areas of Tanzania. [Presentation]. Dar es Salaam, 21-24 February. [Online]. https://www.wmo.int/pages/prog/amp/pwsp/documents/Mahoo_Sokoine.pdf (22 July 2013).

Majule, A.E. and Yanda, P.Z. 2009. Climate change impacts and adaptation: experiences from communities dependent on wetland resources in Bahi wetlands, central Tanzania. In Natural resources contribution to community livelihoods: experiences from selected case studies in Tanzania. A.E. Majule, E.T. Liwenga, R.Y.M. Kangalawe and P.Z. Yanda, Eds. Dar es Salaam: Dar es Salaam University Press.

Mongi, H., Majule, A.E. and Lyimo, J.G. 2010. Vulnerability and adaptation of rain-fed agriculture to climate change and variability in semi-arid Tanzania. African Journal of Environmental Science and Technology, 4(6): 371-381.

Mutekwa, V.T. 2009. Climate change impacts and adaptation in the agricultural sector: the case of smallholder farmers in Zimbabwe. Journal of Sustainable Development in Africa, 11(2): 237-256.

Naess, L.O. 2013. The role of knowledge in adaptation to climate change. WIREs Climate Change, 4(2): 99-106.

Nyong, A., Adesina, F. and Elasha, O.B. 2007. The value of indigenous knowledge in climate change mitigation and adaptation strategies in the African Sahel. Mitigation Adaptation Strategies Global Change, 12: 787-797.

Orindi, V. A. and Murray, L. A. 2005. Adaptation to climate change in East Africa: a strategic approach, international institute for environment development. Gatekeeper Series 117. [Online]. http://pubs.iied.org/pdfs/9544IIED.pdf (20 September 2012).

Orlove, B.S., Chiang, J.C.H. and Cane, M.A. 2000. Forecasting Andean rainfall and crop yield from the influence of El Niño on Pleiades visibility. Nature, 403: 68-71.

Orlove, B., Roncoli, C., Kabugo, M. and Majugu, A. 2010. Indigenous climate knowledge in southern Uganda: the multiple components of a dynamic regional system. Climate Change, 100(2): 243-265.

Rogers, E.M. 2003. Diffusion of innovations. $5^{\text {th }}$ ed. New York: Free Press.

Roncoli, C. 2006. Ethnographic and participatory approaches to research on farmers' responses to climate predictions. Climate Research, 33: 81-99. 
Roncoli, C., Ingram, K. and Kirshen, P. 2002. Reading the rains: local knowledge and rainfall forecasting in Burkina Faso. Society and Natural Resources: an international Journal, 15(5): 409-427.

Slegers, M.F.W. 2008. Exploring farmers' perceptions of drought in Tanzania and Ethiopia. PhD thesis. University of Wageningen. [Online]. http://edepot.wur.nl/14361 (3 June 2012).

Speranza, C.I., Kiteme, B., Ambenje, P., Wiesmann, U. and Makali, S. 2010. Indigenous knowledge related to climate variability and change: insights from droughts in semi-arid areas of former Makueni district, Kenya. Climate Change, 100: 295-315.

Tarhule, A. and Lamb, P.J. 2003. Climate research and seasonal forecasting for West Africans: perceptions, dissemination and use? Bulletin of American Meteorological Society, 84(12): 1741-1759.

United Republic of Tanzania (URT). 2007. National Adaptation Programme of Action. Dar es Salaam: Government Printer. [Online]. http://unfccc.int/resource/docs/napa/tza01.pdf (1 August 2013).

Ziervogel, G. and Opere, A. 2010. Eds. Integrating meteorological and indigenous knowledge-based seasonal climate forecasts for the agricultural sector: lessons from participatory action research in sub-Saharan Africa. Ottawa, Canada: International Development Research Centre. 